\title{
THE PRODUCTION OF OEDEMA DISEASE AND DIARRHOEA IN WEANED PIGS BY THE ORAL ADMINISTRATION OF ESCHERICHIA COLI: FACTORS THAT INFLUENCE THE COURSE OF THE EXPERI- MENTAL DISEASE
}

\author{
H. Williams Smith and Sheila Halls \\ Animal Health Trust, Stock, Essex
}

\section{Plate III}

ALTHOUGH the evidence incriminating certain serotypes of Escherichia coli in the aetiology of oedema disease in pigs is very strong, efforts to reproduce it by the oral administration of cultures of this organism have failed (see Sojka, 1965, p. 109). Outbreaks of oedema disease associated with the same haemolytic serotype of $E$. coli, $\mathrm{O} 141$ : K85ac, were recently observed in one fattening unit in several successive batches of 8-10-wk-old pigs that had been purchased from the same small breeding farm. When pigs brought to the laboratory from the breeding farm (farm $J$ ) were given this strain of $E$. coli by mouth they developed a condition identical with oedema disease. The results of these experiments and of studies on the pathogenesis of the disease are reported in this paper, which also includes observations on (i) the influence of diet on the course of the disease, and (ii) the antibody levels and immune status of pigs from farm $\mathbf{J}$ and from other breeding farms. At an early stage in the experimental disease, most of the pigs experienced an attack of diarrhoea. This was not surprising because the O141: K85ac strain is enterotoxigenic (Smith and Halls, 1967a and $b$ ). Consequently, we were able to make observations on $E$. coli diarrhoea as well as on oedema disease.

\section{MATERIALS AND METHODS}

Pigs. The pigs were of the Large White breed weighing approximately $16 \mathrm{~kg}$ when brought to the laboratory at $8 \mathrm{wk}$ of age. Two weeks previously they had been weaned on to a commercial ration (see below) at farm $\mathbf{J}$. At the laboratory they were kept in groups in portable metal pens with solid sides and floors. Between experiments, these pens were sterilised by means of a blow-lamp and moved to a new site. This was essential because of the highly infectious nature of the O141: K85ac strain of E. coli.

Diets. Two principal diets were employed, both being given ad libitum. One, referred to as the commercial ration, was made by a large feed-compounding firm. It consisted of fish meal, 5 per cent.; meat meal, $2 \frac{1}{2}$ per cent.; ground-nut meal, $1 \frac{1}{4}$ per cent.; middlings, barley, wheat and milo meals, tricalcium phosphate, limestone flour and trace element and vitamin supplement to 100 per cent. The other diet, referred to as the control ration, consisted of fish meal, 10 per cent., and barley meal, 90 per cent. All the pigs under experiment were fed on the control diet unless otherwise stated.

Received 8 Nov. 1967; accepted 22 Dec. 1967.

J. MED. MICROBIOL.-VOL. 1 (1968) 
Inoculation method. Nutrient agar slopes inoculated heavily with the $0141: \mathrm{K} 85 \mathrm{ac}$ strain were incubated at $37^{\circ} \mathrm{C}$ for $6 \mathrm{hr}$ and the bacterial growth washed off with phosphate buffer, $p \mathrm{H} 7.0\left(\mathrm{Na}_{2} \mathrm{HPO}_{4}, 1.5 \mathrm{~g} ; \mathrm{KH}_{2} \mathrm{PO}_{4}, 0.85 \mathrm{~g} ; \mathrm{H}_{2} \mathrm{O}, 1\right.$ litre) and adjusted to contain 1010 viable organisms per $5 \mathrm{ml}$. This amount was placed on the back of the mouth of each pig.

The examination of pigs before and after inoculation. Rectal contents of all pigs were examined for the presence of organisms belonging to those serotypes of $E$. coli considered pathogenic for pigs (see Sojka, p. 118) at least twice before they were put under experiment; such organisms were never found. Afterwards, counts of $0141: \mathrm{K} 85 \mathrm{ac}$ organisms and of the general $E$. coli population were made daily on rectal contents. The appetite, rectal temperature and the health status of each pig were assessed and recorded daily. A serum sample was obtained from each pig before it was put under experiment and again when it was killed or when the experiment was terminated. These samples were held at $-20^{\circ} \mathrm{C}$ until required for serological studies.

Because of the changes in the structure and bacterial flora of the intestine that take place soon after death (Smith, 1962; Smith and Jones, 1963), bacteriological and pathological examinations were made only on killed pigs. Consequently, all severely ill pigs were watched carefully and when death was imminent they were killed by intravenous injection of pentobarbitone sodium. The abdomen was quickly opened and ligatures were applied to the oesophagus and duodenum close to the stomach, to the ileocaecal junction, to the posterior ectum and at numerous points along the small intestine. The whole alimentary tract was then removed and unravelled; the small intestine was arranged into 7 equal parts and the ligatures not needed to separate these parts were removed. The contents of the body and the antrum of the stomach and of each part of the small intestine, the colon and rectum were removed and bacterial counts performed on them. Their character and their approximate volumes were noted and their $p \mathrm{H}$ values determined with a $p \mathrm{H}$ meter. In some pigs bacterial counts were determined for material obtained from the intestinal wall: for this purpose the mucosa of the intestine was washed gently with a little normal saline at $39^{\circ} \mathrm{C}$; it was then scraped with a scalpel and the material so removed was diluted 10 times with phosphate buffer and shaken in a shaking machine with glass beads before viable bacterial counts were done (see below).

Pieces of tissue from the stomach, the 7 parts of the small intestine, the colon and several of the internal organs were placed in 4 per cent. formaldehyde within $15 \mathrm{~min}$. of the animal being killed. The stomach wall was then carefully examined for the presence of submucosal oedema.

Examination of rectal contents for the O141: K85ac strain of E. coli. Rectal swabs were streaked over the surface of a dried blood agar plate which was then incubated at $37^{\circ} \mathrm{C} \mathrm{for}$ 18-24 hr. The search for colonies of the 0141: K85ac strain was facilitated by the fact that they were haemolytic and of a mucoid consistency. Identification was achieved by submitting colonies to slide agglutination tests with O141: K85ac antiserum. Haemolytic colonies that did not agglutinate were tested with antisera against other serotypes of $E$. coli pathogenic for pigs. These were prepared by Mr W. J. Sojka of the Central Veterinary Laboratory of the Ministry of Agriculture.

Enumeration of E. coli and lactobacilli in the contents of the alimentary tract. This was done by a modification of the method of Miles and Misra (Miles, Misra and Irwin, 1938). Two media were employed, blood agar for enumerating the non-haemolytic $E$. coli and the haemolytic O141 : K85ac organisms, and Rogosa agar for enumerating lactobacilli.

Examination of serum samples for antibodies. The $\mathrm{O}$ antibody content of serum samples was measured by a direct agglutination tube test and an indirect haemagglutination tube test. $\mathrm{K}$ antibodies were measured by slide and tube agglutination tests. All the tests were performed by the methods of Sojka (p. 210).

The anti-haemolysin content of serum samples was measured by the method of Smith (1963). The haemolysin used in these tests was prepared from the O141: K85ac strain itself.

Before measuring their bactericidal antibody content, serum samples were inactivated 
by holding them at $60^{\circ} \mathrm{C}$ for $1 \mathrm{hr}$. Doubling dilutions of each sample were then made in $0 \cdot 2$-ml amounts in normal saline and an equal volume of the serum of a newly born colostrumdeprived calf was added to provide complement. To each dilution were added 2000 organisms of strain $0141: \mathrm{K} 85 \mathrm{ac}$ in $0.02 \mathrm{ml}$ of normal saline. This inoculum was prepared from an 18-hr broth culture. The dilutions were incubated for $3 \mathrm{hr}$ at $37^{\circ} \mathrm{C}$ and $0.02 \mathrm{ml}$ spread over half the surface of a petri plate containing MacConkey agar. The plates were incubated at $37^{\circ} \mathrm{C}$ overnight and colony counts performed. The highest dilution in which the bacterial content had been reduced by more than 75 per cent. was recorded as the bactericidal antibody titre.

\section{RESULTS \\ History of breeding farm $J$ and fattening unit}

The breeding herd had been established in 1932 with 5 sows, purchased from one farm, and a boar. The only purchases made since that time were replacements for the boar. Sow replacements were made from within the herd itself, the number of sows varying between 5 and 14. In 1967 the herd contained 5 sows, 3 of which were litter sisters. From 1961 to 1965,40 batches of 8 -wk-old pigs, varying in number from 6 to 20 , were taken to the fattening unit which was 12 miles away. Here, they were fed on the commercial ration which was the same diet as they had received for the previous $2 \mathrm{wk}$ at farm J. No cases of oedema disease occurred in any of the pigs in the first 35 batches, but outbreaks occurred in 4 of the last 5 batches shortly after they were brought to the unit. There were 62 pigs in these 5 batches and 21 of them died. The strain of E. coli incriminated in all 4 outbreaks was the O141: K85ac serotype. After the last outbreak, 2 batches of 20 and 9 pigs were moved from farm $\mathbf{J}$ to 2 different fattening units where they remained for $3 \mathrm{wk}$. During this time they were fed on the commercial ration. They showed no departure from normal health and bacteriological investigation of their faeces at the beginning and the end of this period did not yield the O141: K85ac strain. After the last outbreak at the fattening unit, 2 batches of 8-wk-old pigs from different breeding farms were moved on to it. They showed no clinical signs of oedema disease during 4 mth there.

\section{Experimental reproduction of oedema disease}

One litter of 8-wk-old pigs was divided into 2 groups immediately it was brought to the laboratory. One group of 5 pigs was given the O141: K85ac strain orally and the remaining 4 pigs were not. Both groups were fed on the commercial ration, i.e., the same diet as they had received for the last 2 wk at farm J. All 5 inoculated pigs suffered from diarrhoea for 1 or 2 days within 3-6 days after inoculation. During this time and for 2 days afterwards they ate very little food. Two of them developed the typical clinical signs of oedema disease, i.e., swelling of the eyelids and ataxia, one at 7 days, and one at 9 days after inoculation when they were both killed. At necropsy, the full stomach and empty small intestines characteristic of oedema disease were noted in both pigs. The pig killed on the 7th day had extensive submucosal oedema of the cardiac region of the stomach (see the figure); gastric oedema was not present in the other pig. The 4 control pigs remained healthy during the period of observation. 
In an experiment similar to the one described above, there were 3 experimental and 2 control pigs from the same litter. All 5 pigs were fed on the control ration. The 3 inoculated pigs suffered from profuse diarrhoea and anorexia and then developed the typical clinical signs of oedema disease. The disease was sufficiently severe in only 2 of the pigs to justify killing them, one at 7 days and one at 9 days after inoculation. At necropsy, both pigs had full stomachs and empty small intestines; gastric oedema was present in the pig killed at 7 days, but not in the one killed at 9 days. The 2 uninoculated control pigs remained well.

\section{The characteristics of the disease produced by oral inoculation of the O141: K85ac strain}

The principal clinical signs and necropsy findings and estimations of the numbers of viable $E$. coli $\mathrm{O} 141: \mathrm{K} 85 \mathrm{ac}$ in the contents of different parts of the alimentary tract in 24 pigs that were killed at different times after oral inoculation with this strain are shown in table $\mathrm{I}$.

A constant sign indicating the onset of clinical infection was anorexia. It lasted several days in the pigs that recovered and for the rest of the lives of those in which the disease would have been fatal had they not been killed. The diarrhoea was usually severe but it was of short duration. In only one pig was it fatal. In most pigs it was no longer present when signs of nervous involvement became apparent. Although the only nervous sign recorded in table I is ataxia, this was accompanied by varying degrees of mental confusion. The ataxia, which did not occur until 5 days after inoculation, was usually progressive; affected pigs soon became completely recumbent. Severe dyspnoea was usually present at this final stage. The rectal temperatures of 14 of the pigs were recorded daily. The readings were always within the normal range. There was no evidence that body temperature was influenced by the disease process.

No abnormalities were noted at necropsy in any of the 4 pigs killed 1-3 days after inoculation. In 2 of those examined at 4 days (no. 7 and 8) and in 2 examined at 5 days (no. 9 and 10) the contents of the small intestine were excessively fluid. The small-intestinal mucous membrane in these 4 pigs was macroscopically normal. Apart from extensive gastric oedema, the principal abnormalities noted in the pigs killed after this time were in the contents of the alimentary tract. Despite the fact that they had not eaten for several days, their stomachs usually contained a large amount of food which was dry in consistency and stale-smelling. By contrast, their small intestines were almost completely empty, containing only a little watery bile-stained fluid. The appearances of the small intestines and of their blood vessels resembled those of starved pigs.

It was not until 3 days after inoculation that very large numbers of $E$. coli O141: K85ac were found in the contents of the more anterior regions of the small intestine. These high numbers were a feature of the diarrhoeic phase of the disease. High concentrations were also found in most but not all (e.g., no. 15,17 and 24) of the pigs killed during the later oedema disease phase when the alimentary tract was non-functional. However, as the small intestine was 


\section{ESCHERICHIA COLI INFECTION IN PIGS}

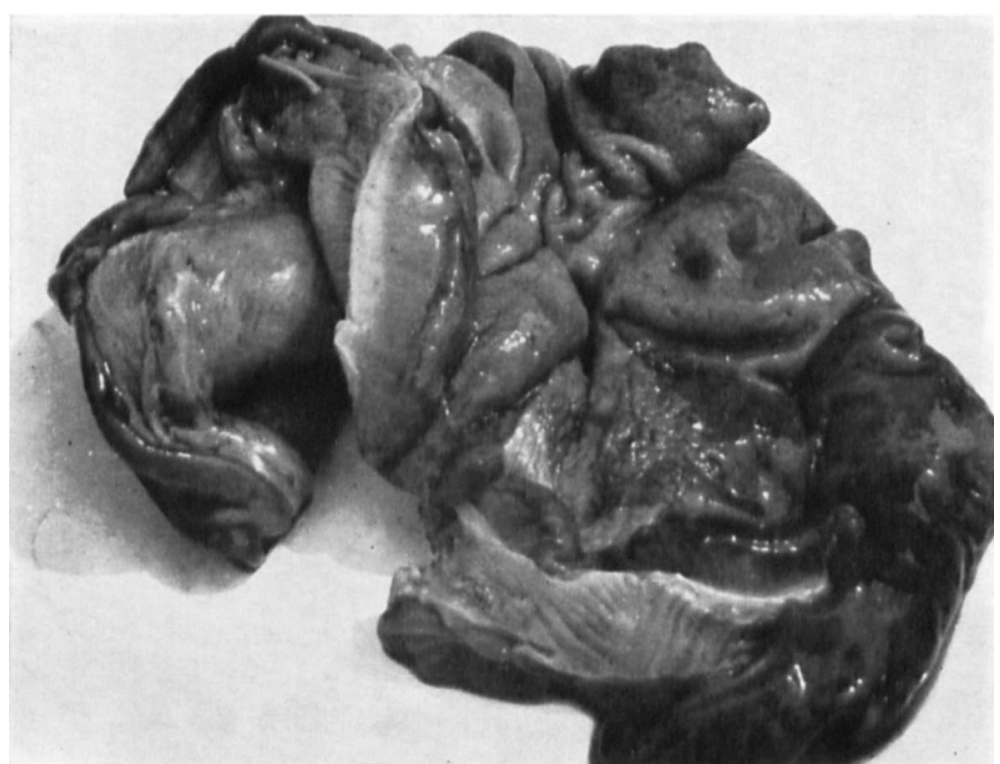

FIGURE.-Stomach of pig affected with oedema disease. Extensive submucosal oedema seen in the cut surface of the stomach wall. $\times \frac{1}{2}$. 
Clinical signs and necropsy findings in pigs killed at different times after oral inoculation of E. coli O141: K85ac

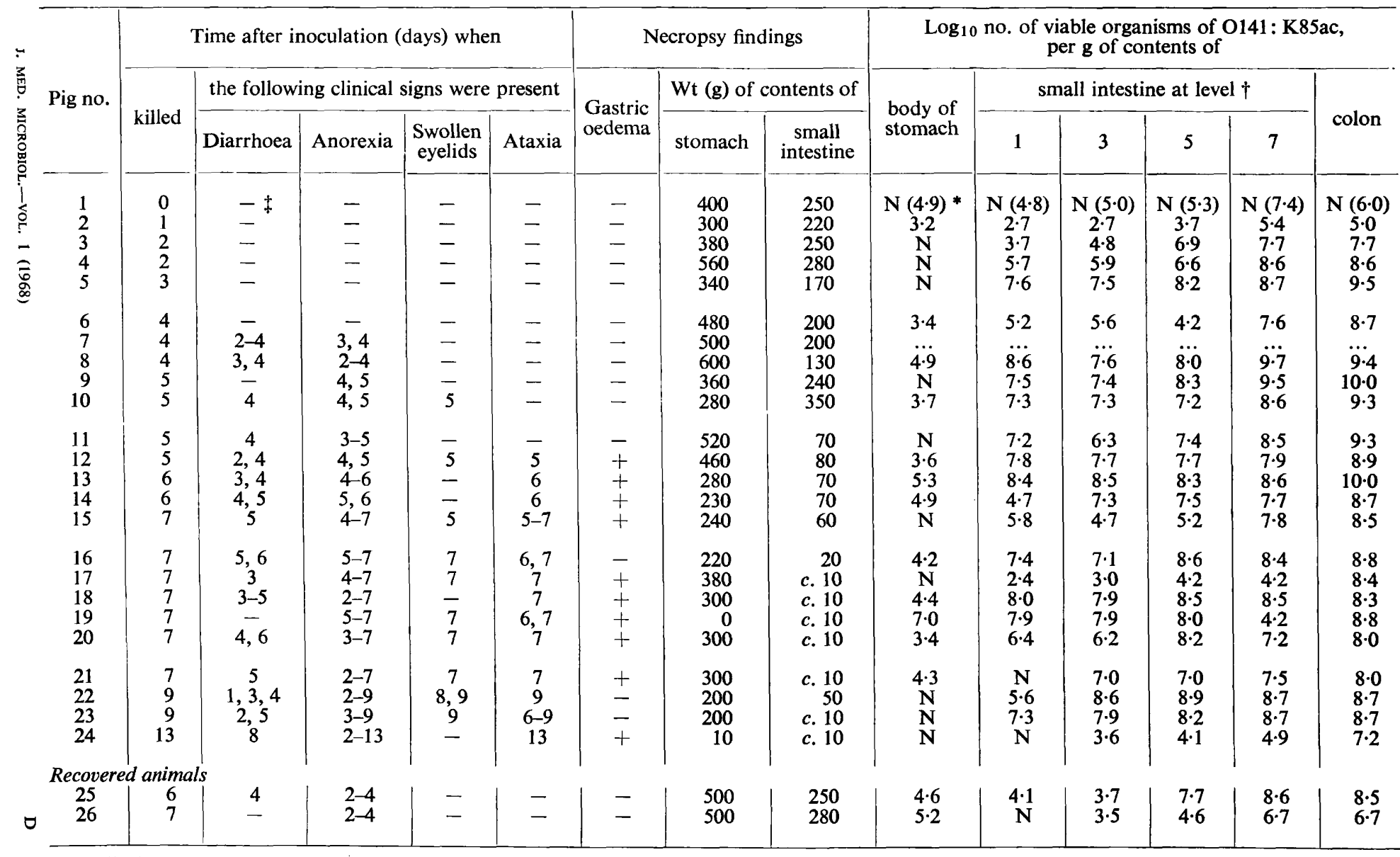

All pigs recorded as being ataxic were seriously ill when killed; it was unlikely that most of them would have lived for another day. Pigs 17, 20 and 21 had oedema of the mesentery of the colon as well as of the stomach.

$* \mathrm{~N}=$ No viable bacteria in $0.02 \mathrm{~g}$; i.e., $\log _{10}$ no. organisms per $\mathrm{g}<1.7$; figures in brackets are of the non-pathogenic $E$. coli flora.

$\dagger$ The small intestine was divided into 7 equal parts; part 1 was nearest to the stomach and part 7 to the colon. No $E$. coli counts are given for pig 7; this animal had died from severe diarrhoea.

$\ddagger-=$ Absent $;+=$ present. 
practically empty at this time, the total numbers of $E$. coli $\mathrm{O} 141$ : K85ac present were obviously very much lower than they were during the diarrhoeic phase. Small numbers of the inoculated strain were occasionally found in the mesenteric lymph-glands of the pigs. The organism was never found in the spleen.

Apart from the $E$. coli component, the bacterial flora of pigs killed early in the disease process, when the alimentary tract was still functional, was quantitatively and qualitatively similar to that found in healthy pigs (Smith and Jones; Smith, 1965). In some of these pigs larger numbers of $E$. coli O141: K85ac, but

TABLE II

The numbers of viable E. coli O141: K85ac and lactobacilli in the contents and in scrapings of the wall of the small intestine of a pig killed 5 days after inoculation

\begin{tabular}{|c|c|c|c|}
\hline \multirow{2}{*}{\multicolumn{2}{|c|}{ Small-intestinal material examined }} & \multicolumn{2}{|c|}{$\log _{10}$ no. of organisms per $g$ of materia } \\
\hline & & E. coli O141: K85ac & Lactobacilli \\
\hline $\begin{array}{l}\text { Contents of part } 1^{*} \\
\text { Wall scrapings of part } i\end{array}$ &.$\quad$. & $\begin{array}{l}7 \cdot 5 \\
8 \cdot 3\end{array}$ & $\begin{array}{l}6 \cdot 3 \\
4 \cdot 6\end{array}$ \\
\hline $\begin{array}{l}\text { Contents of part } 3 \\
\text { Wall scrapings of part } 3\end{array}$ & & $\begin{array}{l}7 \cdot 4 \\
9 \cdot 3\end{array}$ & $\begin{array}{l}6 \cdot 4 \\
4 \cdot 7\end{array}$ \\
\hline $\begin{array}{l}\text { Contents of part } 5 \\
\text { Wall scrapings of part } 5\end{array}$ & : & $\begin{array}{l}8 \cdot 3 \\
8 \cdot 4\end{array}$ & $\begin{array}{l}7 \cdot 3 \\
5 \cdot 9\end{array}$ \\
\hline $\begin{array}{l}\text { Contents of part } 7 \\
\text { Wall scrapings of part } 7\end{array}$ & . & $\begin{array}{l}9 \cdot 5 \\
8 \cdot 7\end{array}$ & $\begin{array}{l}9 \cdot 9 \\
6 \cdot 3\end{array}$ \\
\hline
\end{tabular}

* The small intestine was divided into 7 equal parts; part 1 was nearest to the stomach and part 7 to the colon.

not of lactobacilli, were found in scrapings from the walls of the more anterior regions of the small intestine than in the contents of these regions. The results of such estimations on one pig (no. 9 in table I) are illustrated in table II. Similar results were obtained in some of the pigs killed later when their alimentary tracts were non-functional.

Apart from the 24 pigs referred to above, another 17 were given the O141: K85ac strain. All developed anorexia and diarrhoea, but only 2 became ataxic. In 2 of them killed when they were recovering (no. 25 and 26 in table I) the necropsy findings and the numbers of $E$. coli in their alimentary tracts were similar to those observed in healthy pigs. The remaining 15 made a rapid and complete recovery. The results of estimating daily the numbers of viable O141: K85ac organisms in the rectal contents of these pigs and in those referred to in table I are summarised in table III. Very high numbers were found from the 2 nd to about the 8th day after inoculation. Then the numbers began to decrease until towards the end of the observation period of 14 days the O141: K85ac organisms were outnumbered by the non-pathogenic E. coli of the faecal flora. 
The re-inoculation of pigs recovered from clinical infection with the 0141: K85ac strain

Eight pigs that had recovered from clinical infection with the O141: K85ac strain were again given this strain by mouth 15-18 days after their initial inoculation. They remained perfectly healthy. $E$. coli counts were performed daily on the rectal contents of two of these pigs. The $\log _{10}$ numbers of $E$. coli O141: K85ac organisms per $g$ of faeces at 2 and 3 days after inoculation in one pig were 5.4 and 5.0 and in the other 5.4 and 5.2 respectively. The strain was not found in either of these 2 pigs at subsequent examinations.

TABLE III

The numbers of viable E. coli O141: K85ac in the rectal contents of pigs after oral inoculation of this strain*

\begin{tabular}{c|c|c}
\hline & \multicolumn{2}{|c|}{$\log _{10}$ no. of viable organisms per $\mathbf{g}$} \\
inoculation & Median & Range \\
\cline { 2 - 3 } & & \\
\cline { 2 - 3 } 0 & $\mathrm{~N}(6 \cdot 4) \dagger$ & $\mathrm{N}-\mathrm{N}(4 \cdot 6-7 \cdot 9) *$ \\
1 & $6 \cdot 2$ & $3 \cdot 7-9 \cdot 7$ \\
2 & $8 \cdot 0$ & $5 \cdot 7-9 \cdot 7$ \\
3 & $9 \cdot 1$ & $6 \cdot 2-10 \cdot 1$ \\
4 & $9 \cdot 3$ & $7 \cdot 0-10 \cdot 1$ \\
5 & $9 \cdot 2$ & $6 \cdot 7-9 \cdot 9$ \\
& & $7 \cdot 0-10 \cdot 6$ \\
6 & $8 \cdot 0$ & $4 \cdot 4-9 \cdot 4$ \\
7 & $8 \cdot 3$ & $2 \cdot 7-8 \cdot 9$ \\
8 & $6 \cdot 7$ & $3 \cdot 2-9 \cdot 7$ \\
9 & $6 \cdot 6$ & $4 \cdot 8-8 \cdot 3$ \\
10 & $6 \cdot 7$ & $3 \cdot 3-8 \cdot 6$ \\
11 & $6 \cdot 7$ & $\mathrm{~N}-8 \cdot 7$ \\
12 & $6 \cdot 2$ & $\mathrm{~N}-8 \cdot 0$ \\
13 & $6 \cdot 5$ & $\mathrm{~N}-7 \cdot 7$ \\
14 & $6 \cdot 5$ & \\
\hline
\end{tabular}

* 39 pigs were used in this experiment; 25 of them were killed at various times during its course.

$\dagger \mathrm{N}=$ None found in $0.02 \mathrm{ml}$; in brackets, figures for non-pathogenic $E$. coli.

Four strains of $E$. coli belonging to serotypes generally accepted as being pathogenic for pigs, viz. O138: K81, O139: K82, O141: K85ab,88ab and O147: K89,88ac, were used in experiments with another 8 pigs 23 days after initial inoculation of the O141: K85ac strain. Each of the 4 strains was given to 2 pigs. All 8 pigs showed no resultant sign of ill-health. Small numbers of the inoculated strains were found in the rectal contents of the pigs 1 and 2 days after inoculation, but these strains were not isolated at subsequent examinations.

Four recovered pigs, 2 wk after inoculation of the O141: K85ac strain, were each given a mixture of 6 strains all belonging to different porcine pathogenic serotypes. They remained well. In 3 of the 4 pigs, the $\log _{10}$ numbers of $E$. coli belonging to one or other of the 6 serotypes per $g$ of rectal contents, 
were never higher than 7.8 at 2-7 days after inoculation; they were usually in the region of 6.5 . The corresponding figures for the fourth pig were usually in the region of 8.5-9.5.

\section{The inoculation of pathogenic serotypes of E. coli other than 0141: K85ac into pigs}

Serotype 0141: K85ab,88ab. Two pigs received one strain of this serotype. Both became very ill 2 days after inoculation, the principal signs being anorexia and severe diarrhoea with clinical evidence of dehydration. These signs persisted in one pig for 3 days, after which it recovered. The other pig was killed 4 days after inoculation when it was near death. Large numbers of viable organisms of the inoculated serotype were found in the rectal contents of both pigs at each daily examination. In the one that recovered, the $\log _{10}$ numbers per $\mathrm{g}$ at $1,2,3,4,5$ and 6 days after inoculation were 9.0, 8.8, 9.5, 9.4, 6.7 and $6 \cdot 3$ respectively. The principal abnormality in the pig that was killed was the large amount and very fluid nature of the contents of the small intestine. The $\log _{10}$ numbers of viable organisms of the inoculated serotype per $\mathrm{g}$ of stomach contents and of intestinal content at levels $1,2,3,4,5,6$ and 7 of the small intestine and of the colon were $4 \cdot 3,7 \cdot 4,7 \cdot 2,9 \cdot 0,7 \cdot 5,9 \cdot 0,8 \cdot 7,9.4$ and $9 \cdot 1$ respectively.

Serotype O147: K89,88ac. One pig was given a strain of this serotype and it became ill 2 days later. The course of the disease, the clinical signs and the results of the bacteriological examinations of the rectal contents closely resembled those described for the pig that recovered after inoculation with the O141: K85ab,88ab serotype.

Serotype O138: K81. On the 3rd day after a pig was given a strain of this serotype, it had profuse diarrhoea lasting 1 day. There were no general signs of ill-health. The $\log _{10}$ numbers of viable organisms of the inoculated strain per $g$ of rectal contents $1,2,3,4,5,6,7$ and 8 days after inoculation were $7 \cdot 0,9 \cdot 1,8 \cdot 9$, $9 \cdot 3,8 \cdot 1,8 \cdot 0,8 \cdot 4$ and $6 \cdot 0$ respectively.

Serotype 0139: K82. One pig was given an enterotoxigenic strain of this serotype; most strains of this serotype are non-enterotoxigenic (Smith and Halls, 1967a). This pig had a mild attack of diarrhoea lasting 1 day, 4 days after inoculation; the clinical and bacteriological picture in this pig closely resembled that seen in the pig given the O138: K81 serotype.

Serotype 09: K9. A pig given a strain of this serotype exhibited no signs of ill-health. The inoculated strain was not isolated from its rectal contents.

\section{Attempts to infect pigs from other breeding farms with the O141: K85ac strain}

Eight recently-weaned 8-wk-old pigs were brought to the laboratory from 8 unrelated breeding farms and fed on the commercial ration; previously they had all been receiving diets that differed from this ration and from each other. Three days later they were given the 0141: K85ac strain. Apart from one pig that had diarrhoea without any other signs of ill-health on the 2 nd day after 
TABLE IV

The numbers of viable E. coli O141: K85ac in the rectal contents of 8 pigs from different breeding farms after oral inoculation of this strain

\begin{tabular}{|c|c|c|c|c|c|c|c|c|c|c|c|c|c|c|}
\hline \multirow{2}{*}{$\begin{array}{l}\text { Breeding farm } \\
\text { of origin }\end{array}$} & \multicolumn{14}{|c|}{$\log _{10}$ no. of organisms per $g$ on the following days after inoculation } \\
\hline & 1 & 2 & 3 & 4 & 5 & 6 & 7 & 8 & 9 & 10 & 11 & 12 & 13 & 14 \\
\hline $\begin{array}{l}\text { A } \\
\text { B } \\
\text { C } \\
\text { D } \\
\text { E } \\
\text { F } \\
\text { G } \\
\text { J } \neq\end{array}$ & $\begin{array}{l}6 \cdot 7 \\
8 \cdot 7 \\
6 \cdot 8 \\
4 \cdot 8 \\
5 \cdot 2 \\
7 \cdot 0 \\
5 \cdot 0 \\
5 \cdot 7\end{array}$ & $\begin{array}{l}4 \cdot 7 \\
7 \cdot 2 \dagger \\
6 \cdot 0 \\
5 \cdot 2 \\
6 \cdot 6 \\
6 \cdot 5 \\
7 \cdot 6 \\
8 \cdot 9 \dagger\end{array}$ & $\begin{array}{l}5.0 \\
5.5 \\
6.0 \\
4.4 \\
5 \cdot 2 \\
4.4 \\
7.0 \\
7.9\end{array}$ & $\begin{array}{l}5 \cdot 2 \\
5 \cdot 3 \\
4 \cdot 4 \\
4 \cdot 4 \\
4 \cdot 4 \\
4 \cdot 7 \\
7 \cdot 8 \\
9 \cdot 4\end{array}$ & $\begin{array}{l}4.0 \\
6.0 \\
7 \cdot 2 \\
4 \cdot 0 \\
7 \cdot 0 \\
4 \cdot 0 \\
7 \cdot 0 \\
8 \cdot 7\end{array}$ & $\begin{array}{c}\mathrm{N}^{*} \\
7 \cdot 0 \\
4 \cdot 7 \\
\mathrm{~N} \\
6 \cdot 4 \\
\mathrm{~N} \\
7 \cdot 2 \\
9 \cdot 3\end{array}$ & $\begin{array}{c}\mathrm{N} \\
6 \cdot 7 \\
4 \cdot 7 \\
4 \cdot 7 \\
6 \cdot 0 \\
4 \cdot 3 \\
7 \cdot 0 \\
8 \cdot 2\end{array}$ & $\begin{array}{c}\mathrm{N} \\
4 \cdot 4 \\
5 \cdot 7 \\
5 \cdot 0 \\
5 \cdot 7 \\
4 \cdot 6 \\
4 \cdot 7 \\
7 \cdot 9\end{array}$ & $\begin{array}{l}5 \cdot 5 \\
5 \cdot 7 \\
4 \cdot 6 \\
5 \cdot 7 \\
7 \cdot 5 \\
6 \cdot 0 \\
5 \cdot 9 \\
7 \cdot 7\end{array}$ & $\begin{array}{l}5.7 \\
5.6 \\
5.4 \\
4.7 \\
6.2 \\
5.5 \\
6.7 \\
6.8\end{array}$ & $\begin{array}{c}\mathrm{N} \\
5 \cdot 2 \\
5 \cdot 6 \\
4 \cdot 5 \\
5 \cdot 6 \\
4 \cdot 0 \\
5 \cdot 3 \\
7 \cdot 2\end{array}$ & $\begin{array}{c}N \\
5 \cdot 4 \\
N \\
5 \cdot 0 \\
5 \cdot 5 \\
5 \cdot 0 \\
5 \cdot 2 \\
7 \cdot 0\end{array}$ & $\begin{array}{c}\mathbf{N} \\
5 \cdot 7 \\
4 \cdot 7 \\
\mathbf{N} \\
5 \cdot 7 \\
3 \cdot 0 \\
7 \cdot 6 \\
6 \cdot 5\end{array}$ & $\begin{array}{c}\mathrm{N} \\
4 \cdot 4 \\
5 \cdot 5 \\
4 \cdot 0 \\
6 \cdot 3 \\
4 \cdot 5 \\
5 \cdot 3 \\
6 \cdot 6\end{array}$ \\
\hline
\end{tabular}

$* \mathrm{~N}=$ No $0141: \mathrm{K} 85 \mathrm{ac}$ organisms found in $0.02 \mathrm{~g} . ; \quad t=$ diarrhoea present.

$\$$ Farm $\mathbf{J}$ is the breeding farm from which the pigs in all the other experiments were obtained.

\section{TABLE V}

The mean levels of antibody against E. coli 0141 : K85ac in the serum of 3 groups of 8 pigs before inoculation of this strain and the changes detected after inoculation (ranges in brackets)

\begin{tabular}{|c|c|c|c|c|c|c|c|c|c|c|}
\hline \multirow[b]{2}{*}{ Group * } & \multicolumn{5}{|c|}{ Nature and titre of antibody detected before inoculation } & \multicolumn{5}{|c|}{ Factor by which antibody titre increased after inoculation $\dagger$} \\
\hline & $\mathbf{K}$ & $\mathbf{O}$ & $\begin{array}{l}\text { Indirect } \\
\text { haemagglut- } \\
\text { inating }\end{array}$ & $\begin{array}{c}\text { Anti- } \\
\text { haemolysin }\end{array}$ & Bactericidal & K & $\mathbf{O}$ & $\begin{array}{c}\text { Indirect } \\
\text { haemagglut- } \\
\text { inating }\end{array}$ & $\begin{array}{c}\text { Anti- } \\
\text { haemolysin }\end{array}$ & Bactericidal \\
\hline A: Pigs that died . & $\stackrel{8}{8}$ & $\begin{array}{c}<8 \\
(<8-<8)\end{array}$ & $\begin{array}{c}<8 \\
(<8-40)\end{array}$ & $\begin{array}{c}128 \\
(64-256)\end{array}$ & $\begin{array}{c}4 \\
(1-8)\end{array}$ & $\begin{array}{c}1 \\
(1-4)\end{array}$ & $\begin{array}{c}1 \\
(1-1)\end{array}$ & $\underset{(1-1)}{1}$ & $\begin{array}{c}3 \\
(1-4)\end{array}$ & $\begin{array}{c}20 \\
(1-40)\end{array}$ \\
\hline $\begin{array}{l}\text { B: Pigs that } \\
\text { recovered }\end{array}$ & $\begin{array}{c}8 \\
(8-64)\end{array}$ & $\begin{array}{c}<8 \\
(<8-<8)\end{array}$ & $\begin{array}{c}<8 \\
(<8-<8)\end{array}$ & $\begin{array}{c}128 \\
(32-256)\end{array}$ & $\stackrel{2}{(1-8)}$ & $\stackrel{2}{(1-8)}$ & $\begin{array}{c}1 \\
(1-1)\end{array}$ & $\underset{(1-2)}{1}$ & $(1-8)$ & $\begin{array}{c}40 \\
(5-80)\end{array}$ \\
\hline $\begin{array}{c}\text { C: Pigs that showed } \\
\text { no signs of } \\
\text { ill-health }\end{array}$ & $\stackrel{8}{(8-32)}$ & $\begin{array}{c}<8 \\
(<8-<8)\end{array}$ & $\begin{array}{c}<8 \\
(<8-<8)\end{array}$ & $\begin{array}{c}64 \\
(32-128)\end{array}$ & $\stackrel{2}{(1-8)}$ & $\underset{(1-8)}{1}$ & $\begin{array}{c}1 \\
(1-1)\end{array}$ & $\mathbf{1}$ & $\begin{array}{c}1 \\
(1-1)\end{array}$ & $\begin{array}{c}1 \\
(1-1)\end{array}$ \\
\hline
\end{tabular}

* The pigs in groups $A$ and $B$ came from the breeding farm $J$. The group $C$ pigs are the ones featured in table IV that came from different breeding farms.

$\dagger$ 5-9 days after inoculation in the case of the group A pigs when they were near death; approximately 16 days in the case of the group $B$ and $C$ pigs. 
inoculation, all the pigs remained perfectly well during the 14-day observation period. All 8 pigs made normal weight gains.

The results of daily estimations of the numbers of viable O141: K85ac organisms in the rectal contents of 7 of the pigs are illustrated in table IV; the remaining pig had fairly high numbers of haemolytic $E$. coli, not belonging to a pathogenic serotype, in its rectal contents and this made it difficult to estimate the numbers of O141:K85ac organisms present. The results of similar examinations on an inoculated pig, a typical example, from farm $J$ are included for comparison. After the 1st day, O141: K85ac organisms were almost invariably much more numerous in the rectal contents of this animal than in the rectal contents of the pigs from the other breeding farms. In the latter pigs the viable 0141 : K85ac organisms were indeed often outnumbered by the nonpathogenic normal E. coli flora.

\section{Antibody to E. coli O141: K85ac in the sera of pigs before and after inoculation of this strain}

The results of estimating the $\mathrm{O}, \mathrm{K}$, indirect haemagglutinating, haemolysin and bactericidal antibodies to E. coli $\mathrm{O} 141: \mathrm{K} 85 \mathrm{ac}$ in the sera of pigs before and after they were inoculated with this strain are summarised in table V. The pigs are classified according to whether they contracted a fatal infection (group A), developed a clinical infection and then recovered (group B), or showed no signs of ill-health (group C). The pigs obtained from different breeding farms and used in the previous experiment formed the latter group. The post-inoculation specimens were collected from the group A pigs when they were near death, 5-9 days after inoculation, and from the group B and C pigs 16 days after inoculation.

In general, little or no $\mathrm{K}, \mathrm{O}$ or indirect haemagglutinating antibody was found in the sera of the 24 pigs either before or after inoculation. Moderate levels of haemolysin antibody were found in all the pigs before inoculation, there being no difference between the 3 groups in this respect. After inoculation, there was a definite increase in the titre of this antibody in all the group A and $B$ pigs but not in the group $C$ pigs. Low levels of bactericidal antibody were found in the sera of all 24 pigs before inoculation. There was a great increase in the amount of this antibody in the sera of the pigs in groups A and B: the levels in the group $\mathrm{C}$ pigs, however, remained unchanged.

\section{The influence of diet on E. coli O141: K85ac infection}

The results of feeding pigs from farm $J$ on different diets and then administering the O141: K85ac strain are summarised in table VI. Barley fibre was used in this experiment: it is largely indigestible and was obtained from the surface of barley grains during the manufacture of " pearl barley"; a satisfactory degree of palatability was achieved by adding a small amount of saccharin. Three litters of pigs were used in the experiment, some pigs in each litter being given the control ration of barley meal plus 10 per cent. fish meal. The course of the disease was the same in the 14 pigs given ad libitum either barley meal 
alone or supplemented with 10 or 20 per cent. of fish meal. In contrast, the pigs given $150 \mathrm{~g}$ of barley meal plus 10 per cent. fish meal twice daily, representing approximately one-third of the total daily food intake of pigs of their size fed ad libitum, showed no signs of ill-health. Similarly, the pigs fed on barley fibre ad libitum remained healthy after the challenge dose, as did 2 of the 3 fed on barley fibre plus 10 per cent. fish meal; the third pig had diarrhoea for 1 day.

TABLE VI

The effect of feeding different diets to pigs on the response to oral challenge with E. coli O141: K85ac

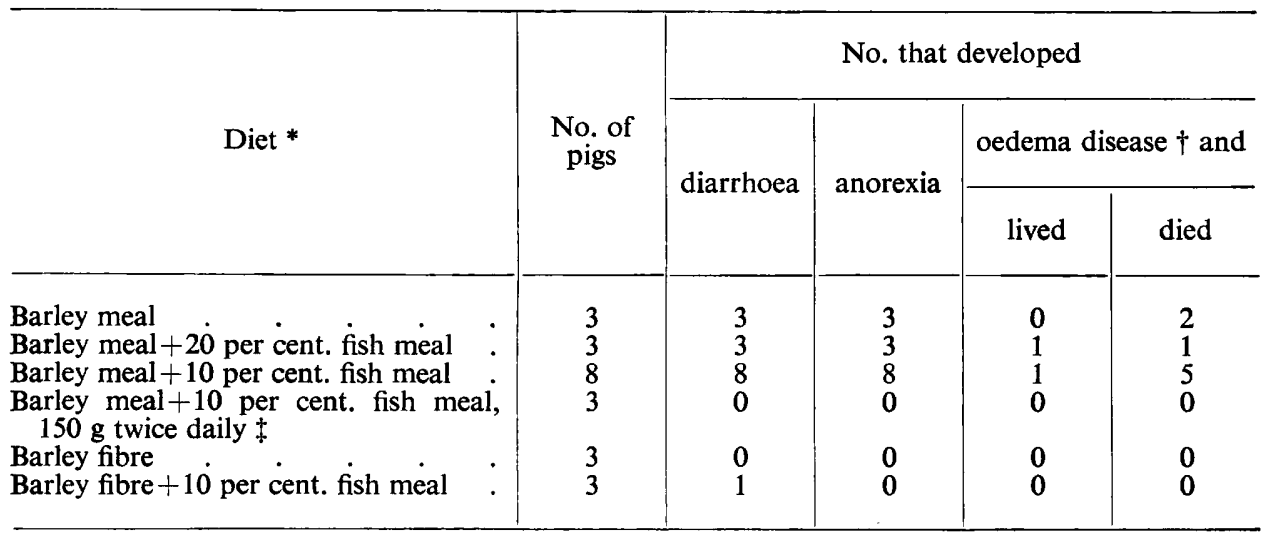

* The administration of the diets was commenced 3 days before inoculation.

$\dagger$ Diagnosed by the presence of swollen eyelids and/or ataxia in the pigs that lived.

\$ The other diets were offered ad libitum.

The results of daily estimates of viable $\mathrm{O} 141: \mathrm{K} 85 \mathrm{ac}$ organisms in the rectal contents of the pigs referred to above are summarised in table VII. High numbers were found in the pigs fed, ad libitum, on barley meal alone or with 10 or 20 per cent. fish meal added. Much lower counts were found in the pigs receiving restricted amounts of the barley meal plus 10 per cent. fish meal ration and in the pigs fed on barley fibre. Low numbers of the challenge strain were also found in 2 of the 3 pigs fed on barley fibre plus 10 per cent. fish meal. High numbers were found in the third animal; this was the pig that had diarrhoea.

The results obtained with another inoculated pig fed on $150 \mathrm{~g}$ of barley meal plus 10 per cent. fish meal twice daily are not included in tables VI and VII. This pig showed no signs of ill-health during the first 5 days after inoculation, yet the numbers of O141: K85ac organisms in its rectal contents were very high: the $\log _{10}$ numbers per $\mathrm{g}$, on days $1,2,3,4$ and 5 after challenge, were $7 \cdot 1,9 \cdot 7,9 \cdot 5,8 \cdot 7$ and $9 \cdot 1$ respectively. In view of this apparent discrepancy the pig was killed on the 5th day. No abnormalities were noted at necropsy. The $\log _{10}$ numbers of viable O141: K85ac organisms per $\mathrm{g}$ of contents in the small intestine at levels $1,3,5$ and 7 were only $2 \cdot 7,2 \cdot 7,2 \cdot 8$ and $5 \cdot 9$ respectively; these data indicate that in this pig the large numbers of the challenge strain 
TABLE VII

The mean numbers (ranges in brackets) of viable E. coli O141: K85ac in the rectal contents of pigs fed on different diets and given this strain orally

\begin{tabular}{|c|c|c|c|c|c|c|c|c|c|}
\hline \multirow{2}{*}{ Diet * } & \multirow{2}{*}{$\begin{array}{l}\text { No. of } \\
\text { pigs }\end{array}$} & \multicolumn{8}{|c|}{$\log _{10}$ no. of $0141: \mathrm{K} 85 \mathrm{ac}$ organisms per $\mathrm{g}$ of rectal contents on the following days after inoculation } \\
\hline & & 1 & 2 & 3 & 4 & 5 & 6 & 7 & 8 \\
\hline Barley meal . & 3 & $\begin{array}{c}5 \cdot 2 \\
(5 \cdot 0-5 \cdot 5)\end{array}$ & $\begin{array}{c}6 \cdot 5 \\
(5 \cdot 7-6 \cdot 5)\end{array}$ & $\begin{array}{c}6.7 \\
(\mathbf{N}-7.9)\end{array}$ & $\begin{array}{c}8.9 \\
(6 \cdot 9-9 \cdot 1)\end{array}$ & $\begin{array}{c}9 \cdot 2 \\
(7 \cdot 2-9 \cdot 3)\end{array}$ & $\begin{array}{c}9 \cdot 0 \\
(8 \cdot 0-9 \cdot 3)\end{array}$ & $\begin{array}{c}8 \cdot 6 \\
(7 \cdot 6-8 \cdot 9)\end{array}$ & $\begin{array}{c}8.9 \\
(8 \cdot 0-8.9)\end{array}$ \\
\hline $\begin{array}{l}\text { Barley meal }+20 \text { per cent. } \\
\text { fish meal }\end{array}$ & 3 & $\begin{array}{c}6 \cdot 2 \\
(5 \cdot 7-6 \cdot 2)\end{array}$ & $\begin{array}{c}6 \cdot 4 \\
(\mathrm{~N}-8 \cdot 5)\end{array}$ & $\begin{array}{c}7 \cdot 6 \\
(7 \cdot 5-9 \cdot 1)\end{array}$ & $\begin{array}{c}9 \cdot 3 \\
(8 \cdot 4-9 \cdot 4)\end{array}$ & $\begin{array}{c}8 \cdot 2 \\
(7 \cdot 9-8 \cdot 7)\end{array}$ & $\begin{array}{c}8 \cdot 0 \\
(7 \cdot 6-8 \cdot 2)\end{array}$ & $\begin{array}{c}8.0 \\
(7 \cdot 0-8 \cdot 9)\end{array}$ & $\begin{array}{c}6.9 \\
(6.9-7 \cdot 9)\end{array}$ \\
\hline $\begin{array}{l}\text { Barley meal }+10 \text { per cent. } \\
\text { fish meal }\end{array}$ & 8 & $\begin{array}{c}5 \cdot 7 \\
(3 \cdot 7-8 \cdot 9)\end{array}$ & $\begin{array}{c}8 \cdot 9 \\
(6 \cdot 7-9 \cdot 7)\end{array}$ & $\begin{array}{c}8 \cdot 4 \\
(7 \cdot 0-9 \cdot 9)\end{array}$ & $\begin{array}{c}9 \cdot 3 \\
(8 \cdot 9-9 \cdot 8)\end{array}$ & $\begin{array}{c}9 \cdot 0 \\
(8 \cdot 3-10 \cdot 1)\end{array}$ & $\begin{array}{c}8 \cdot 1 \\
(6 \cdot 7-9 \cdot 3)\end{array}$ & $\begin{array}{c}8 \cdot 2 \\
(7 \cdot 2-9 \cdot 0)\end{array}$ & $\begin{array}{c}7 \cdot 0 \\
(4 \cdot 7-7 \cdot 9)\end{array}$ \\
\hline $\begin{array}{l}\text { Barley meal }+10 \text { per cent. } \\
\text { fish meal, } 150 \mathrm{~g} \text { twice } \\
\text { daily } \dagger\end{array}$ & 3 & $\begin{array}{c}7 \cdot 2 \\
(4 \cdot 7-7 \cdot 7)\end{array}$ & $\begin{array}{c}6 \cdot 2 \\
(5 \cdot 2-7 \cdot 2)\end{array}$ & $\begin{array}{c}4 \cdot 7 \\
(N-7 \cdot 5)\end{array}$ & $\begin{array}{c}6 \cdot 0 \\
(\mathrm{~N}-6 \cdot 3)\end{array}$ & $\underset{(\mathrm{N}-7 \cdot 0)}{\mathrm{N} \ddagger}$ & $\stackrel{\mathbf{N}}{(\mathrm{N}-7 \cdot 2)}$ & $\stackrel{N}{N}$ & $\begin{array}{c}\mathbf{N} \\
(\mathbf{N}-7 \cdot 2)\end{array}$ \\
\hline Barley fibre . & 3 & $\underset{(\mathbf{N}-\mathbf{N})}{\mathbf{N}}$ & $\begin{array}{c}\mathbf{7 \cdot 0} \\
(\mathrm{N}-7 \cdot 0)\end{array}$ & $\begin{array}{c}7 \cdot 4 \\
(7 \cdot 0-7 \cdot 7)\end{array}$ & $\begin{array}{c}7 \cdot 7 \\
(7 \cdot 0-7 \cdot 7)\end{array}$ & $\begin{array}{c}7 \cdot 0 \\
(6 \cdot 6-7 \cdot 3)\end{array}$ & $\begin{array}{c}6 \cdot 7 \\
(6 \cdot 4-7 \cdot 0)\end{array}$ & $\begin{array}{c}6 \cdot 0 \\
(5 \cdot 7-7 \cdot 4)\end{array}$ & $\begin{array}{c}5 \cdot 7 \\
(5 \cdot 0-6 \cdot 7)\end{array}$ \\
\hline $\begin{array}{l}\text { Barley fibre }+10 \text { per cent. } \\
\text { fish meal }\end{array}$ & 3 & $\underset{(\mathbf{N}-\mathbf{N})}{\mathbf{N}}$ & $\begin{array}{c}8.5 \\
(8 \cdot 0-8 \cdot 9)\end{array}$ & $\begin{array}{c}\mathbf{8 \cdot 0} \\
(7 \cdot 4-9 \cdot 0)\end{array}$ & $\begin{array}{c}\mathbf{8 \cdot 2} \\
(7 \cdot 6-8 \cdot 2)\end{array}$ & $\begin{array}{c}8 \cdot 2 \\
(8 \cdot 0-9 \cdot 3)\end{array}$ & $\begin{array}{c}\mathbf{7 \cdot 0} \\
(7 \cdot 0-9 \cdot 7)\end{array}$ & $\begin{array}{c}7 \cdot 7 \\
(7 \cdot 7-7 \cdot 8)\end{array}$ & $\begin{array}{c}7.6 \\
(7 \cdot 0-7 \cdot 8)\end{array}$ \\
\hline
\end{tabular}

* The administration of the diets was commenced 3 days before inoculation.

The other diets were offered ad libitum.

$\$ \mathrm{~N}=$ No viable organisms in $0.02 \mathrm{ml}$. 
in the rectal contents were not a true reflection of the degree of multiplication of the 0141: K85ac organisms in the small intestine.

\section{Discussion}

The essential bacteriological feature of the infection produced in the pigs from farm $\mathrm{J}$ by oral inoculation of the O141: K85ac strain of Escherichia coli was proliferation of these organisms in the anterior small intestine. The organisms were not invasive; only occasionally were they found in the mesenteric lymph-glands, and then only in very small numbers. The presence of larger numbers of the challenge strain in scrapings of the walls than in the contents of the small intestine in some pigs indicates that this strain's ability to proliferate in the anterior small intestine may be related to its ability to adhere to the epithelium, a property not possessed by non-pathogenic strains.

The diarrhoea occurred during the period when the numbers of the O141: K85ac organisms in the anterior small intestine were maximal. This is compatible with the view that $E$. coli diarrhoea results from the local action on the intestinal wall of enterotoxin produced by the bacteria (Smith and Halls, 1967a). Oedema disease, in contrast, is generally believed to result from the activity of substances absorbed from the alimentary tract, substances that are produced there by pathogenic $E$. coli. The signs of oedema disease in our pigs did not become apparent until a few days after the diarrhoeic phase, usually when the numbers of the inoculated $E$. coli in their small intestines were relatively low. It therefore seems probable that there is some considerable delay between the absorption of the causative substances and the onset of clinical signs of oedema disease. It is noteworthy in this respect that even when oedema disease is produced by the intravenous injection of $E$. coli extracts there may be a delay of as long as $36 \mathrm{hr}$ before signs of the disease become apparent, a fact that is taken to favour the view that oedema disease results from a direct toxic effect of the causative substances, rather than from an anaphylactic effect (Sojka, 1965, p. 114).

Oedema disease can be produced in pigs by the intravenous injection of a variety of extracts of $E$. coli, including heated ones, extracts of other bacteria and, under certain circumstances, egg albumen (see Sojka, p. 110). However, the nature of the causal substance or substances in natural cases of oedema disease is not known. It is unlikely that the enterotoxin is involved, because it is not believed to be absorbed from the alimentary tract and because some of the strains of $E$. coli that can cause oedema disease, particularly those of serotype O139: K82, do not produce enterotoxin (Smith and Halls, 1967a). It is also unlikely that either $\mathrm{O}$ or $\mathrm{K}$ antigens are the causal substance, because our pigs that died or recovered from clinical infection with the O141: K85ac strain showed no antibody response to these antigens. Sweeney, Sojka and Lloyd (1960), too, failed to demonstrate O or K antibody in the sera of pigs that had recovered from natural oedema disease. Since Lloyd (1957) and Timoney (1957) found that the heating of supernatant fluids of centrifuged intestinal contents of affected pigs destroyed their oedema disease-producing capacity 
on intravenous injection, it is apparent that one should be looking for a substance produced by $E$. coli that is heat-labile. $E$. coli $\alpha$-haemolysin is heatlabile and is almost invariably produced by those strains of $E$. coli that are incriminated in outbreaks of oedema disease. Furthermore, the sera of our pigs that died and of those that recovered from clinical infection with the O141: K85ac strain showed definite increases in anti-haemolysin activity. In view of these facts it is interesting to speculate on the possibility that haemolysin may be the causal substance. If this is so, a direct toxic effect is unlikely because the sera of most pigs have a reasonably high anti-haemolysin content and because intravascular haemolysis is not a feature of oedema disease. An anaphylactic reaction is a more likely mechanism.

Whatever the substance that produces the oedema disease syndrome in an infected pig and whatever its mode of action, our findings indicate that the important factor that determines whether or not oedema disease, and certainly diarrhoea, will result from the entry of enteropathogenic $E$. coli into the alimentary tract is the organism's ability to proliferate in the small intestine. A good illustration of this is the finding that only low numbers of O141: K85ac organisms were in the rectal contents of the 8 pigs from different farms that, with one exception, showed no sign of ill-health after challenge inoculation. A comparison of the serum antibody levels of these pigs with those of the susceptible pigs from farm $\mathbf{J}$ did not provide evidence that antibody is important in determining whether or not proliferation occurs. It is noteworthy in this respect that the farm $\mathbf{J}$ pigs were susceptible to infection with strains of $E$. coli of serotypes other than O141: K85ac. Although recovered pigs were resistant to re-infection this need not be due to the presence of antibody provoked by the initial infection. It is conceivable that the unusual susceptibility of the farm $\mathbf{J}$ pigs, which are fairly closely inbred, may be hereditary in origin. This implies that the epithelium of the small intestine of these pigs is genetically more prone to adhesion by organisms of pathogenic serotypes of $E$. coli than is the epithelium of most other pigs. It is obvious that there are other factors that can influence the adhesion of the organisms to the epithelium. Some have been referred to elsewhere (Smith and Halls, 1967a). One, brought to light in the present studies, is the physiological state of the epithelium as evidenced by the fact that we were able to produce infection consistently in pigs fed ad libitum on the control ration but we were unable to infect pigs fed a restricted amount of this ration. Since we also failed to infect pigs fed ad libitum on barley fibre, which is largely indigestible, it is possible that it is the secretory or absorptive function of the epithelium or both that are concerned in this aspect of bacterial adhesion.

\section{SUMMARY}

Diarrhoea and oedema disease were consistently produced in weaned pigs from one breeding farm, but not in pigs from other farms, by the oral administration of Escherichia coli of serotype O141: K85ac. The disease was characterised by the proliferation of large numbers of these organisms in the small intestines a few days after inoculation. Diarrhoea occurred at this time. Signs of oedema 
disease became evident later when the numbers of the organisms in the small intestine were much lower. These pigs were also susceptible to clinical infection with other pathogenic serotypes of $E$. coli.

No difference was found between the antibody content of the sera of the susceptible pigs and of the pigs from the other breeding farms that were resistant to the experimental disease. No increase in $\mathrm{O}$ or $\mathrm{K}$ antibodies occurred in the sera of the susceptible pigs that died or recovered after inoculation with the O141: K85ac strain; anti-haemolytic and bactericidal antibodies increased considerably.

Variation of the protein content of the ration had no obvious effect on the susceptibility of the pigs to infection, but it was not possible to infect pigs given a restricted diet or fed ad libitum on barley fibre.

We are grateful to Mr T. Humphrey, Miss Diane Poulton and Miss Carole Smith for their capable technical help. Our thanks are also due to Mr L. Abbott, Mrs Esther Johnson, Dr K. C. Sellers, Mr W. J. Sojka and Dr J. R. Walton for help and assistance in various ways. We are pleased to acknowledge the financial help provided by the Agricultural Research Council and the Pig Industry Development Authority.

\section{REFERENCES}

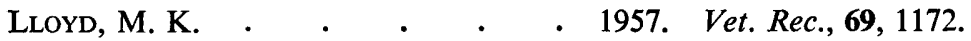

Miles, A. A., Misra, S. S., AND IRwin, 1938. J. Hyg., Camb., 38, 732.

J. $O$.

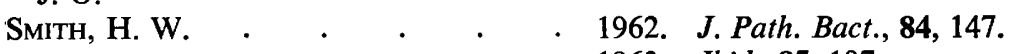

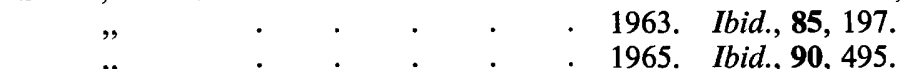

Smith, H. W., AND Halls, Sheila 1967a. Ibid., 93, 499.

" " ",$\quad$ 1967b. Ibid., 93, 531.

SMITH, H. W., AND JoNES, J. "Е. T. 1963. Ibid., 86, 387.

SOJKA, W. J. $\quad . \quad . \quad . \quad$. 1965. Escherichia coli in domestic animals and

SWeeney, E. J., SojKa, W. J., AND 1960. Res. Vet. Sci., 1, 260.

LLOYD, M. K.

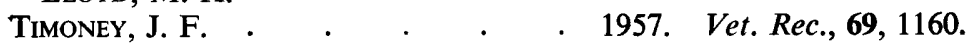

